\title{
Active or passive recovery? Discussing implications of vegetation diversity in unmanaged salt marshes
}

\author{
Diana Almeida ${ }^{\text {a, }}{ }^{*}$, Carlos Neto ${ }^{\text {, }}$ José Carlos Costa ${ }^{b}$ \\ a ZEPHYRUS Research Group, Centro de Estudos Geográficos, Instituto de Geografia e Ordenamento do Território, Edifício IGOT, Rua Branca Edmée Marques, \\ 1600-276 Lisboa, Portugal \\ ${ }^{\mathrm{b}}$ LEAF Research Group, Centro de Investigação em Agronomia, Alimentos, Ambiente e Paisagem, Instituto Superior de Agronomia, Universidade de Lisboa, \\ Tapada da Ajuda, 1349-017 Lisboa, Portugal
}

\section{A R T I C L E I N F O}

Article history:

Received 13 October 2016

Received in revised form

14 March 2017

Accepted 16 April 2017

Available online 18 April 2017

\section{Introduction}

The interest on salt marsh recovery and habitat restoration started to be associated with rapid changes in erosion and accretion rates endangering the human communities that live in the borderline salt marsh (Boorman et al., 2002; Doody, 2013). Lowlying areas left by successive embankments and land reclamation over centuries fail in the absorption of wave energy and in the capacity to accommodate flooding. These aspects started to be valued in a context of climate change, particularly rising sea levels, and these concerns, in the first phase, have led to the construction of breakwater structures (Elliot et al., 2007; Doody, 2013). Nevertheless, these hard measures started to degrade and sustainability issues arose whenever breakwaters and groins needed repairing or reconstruction (Esteves, 2013).

Studies have shown that restoration of salt marshes is a very long process and active intervention may not result in ability to provide ecosystem services equivalent to natural salt marshes (Byers and Chmura, 2007; Garbutt and Wolters, 2008), as well as the vegetation composition to evolve towards floristic recovery (Wolters et al., 2008; Mossman et al., 2012). The success of species emergence can be strongly related with the objectives set for the active recovery. Species introduction would favour some species over others (Strange et al., 2002) but if the target is hydrological

\footnotetext{
* Corresponding author.

E-mail addresses: diana-almeida@campus.ul.pt (D. Almeida), cneto@campus.ul. pt (C. Neto), jccosta@isa.ulisboa.pt (J.C. Costa).
}

restoration (Davy et al., 2011), floristic diversity would not be on the top priorities. Excavating and planting new sites was documented by Zedler and West 2008 as an effort to restore the Tijuana estuary (USA) where short-lived species were overcome by perennials in the absence of topographic heterogeneity (competition) (). Considering Mediterranean marshes, Castillo et al. (2008) demonstrated the competitive potential of invasive Spartina. densiflora in colonizing the center of circular Spartina maritima native species, by altering the vegetation zonation. As Esteves (2014) also demonstrated, the decay of accidentally breached dikes or structures may produce similar results to those of managed realignment. Floristic dissimilarities are found in restoration sites even after long time periods, raising doubts as to the sustainability of these projects (Wolters et al., 2008). A destructed natural habitat can be replaced with an artificial one, comprising biodiversity changes and other environmental impacts, regardless of the ecological outcome (Stagg and Mendelssohn, 2010; Champman and Underwood, 2011).

Concepts used in this investigation incorporated managed realignment as being an example of active recovery, since it results from a deliberated and planned intervention to reach a specific objective. Managed realignment (MR) incorporates a set of actions to compensate for the loss of mudflat and salt marsh habitat associated with multiple land developments (urban construction, tourism growth, port installation, and others) (Chapman and Underwood, 2011; Morris, 2013; Esteves, 2014). It aims to increase flood water storage and serve as wave attenuation (Möller, 2006; Friess et al., 2008); to provide environmental benefits through the re-creation of natural habitats, including landward movement, or to set-back the defence line (Mazik et al., 2010; Esteves, 2014). It is one of the most used and active interventions on coastal wetlands across Europe (broader application in the UK), focusing on baseline re-establishments and is strongly associated with the consequences of rising sea levels for coastal ecosystems. There are other types of active recovery, which concepts are strongly related with the final objective: a) compensatory restoration includes the notion of returning the resources to a predisturbance state as possible aiming to compensate for loss or damage (English et al., 2009); b) Species introduction and/or 
invasive species removal (Mateos-Naranjo et al., 2008; English et al., 2009); c) re-creation follows incentives to the creation of wetlands, with sediment recharges offshore to create mudflats platform to enhance salt marsh developments (Crépin, 2005; Wolters et al., 2008).

On the other hand, the concept of passive recovery derives from the ability of an ecosystem to recover without deliberated human intervention, which can result from historical processes, like abandonment or dyke damaging. Examples of passive recovery are documented by the work of Almeida et al. $(2014,2016)$ and are divided in two types of marshes developing in passive conditions, meaning that non-premeditated or targeted management options were undertaken: $(\mathrm{T})$ tidally restores salt marshes, reporting to marshes which were tidally activated by accidental dyke breaching due to abandonment or lack of maintenance; (E) referring enclosed mix marshes in which salt intrusion is made by capillarity rather than by direct tidal influence - these marshes tend to locate upstream estuaries and were formerly reclaimed for agriculture but the salt ascension compromised the crops and lead to rapid disinterest in these areas. After agriculture abandonment, a mix pattern of fresh and brackish species emerged forming a secondary marsh mosaic. Passive recovery derives from the understanding of recovery as a non-artificial process, meaning that the ecosystem structure and functioning recovers by removing the stressor, whether it is a natural or an artificial stressor. This includes for example, a self-cleaning process after an oil spill (Duarte et al., 2013), or wave damage in an abandoned dykedland salt marsh, allowing tidal dynamics to settle and salt marsh pioneer species to re-install (Almeida et al., 2014).

The hypothesis guiding this research posits that salt marsh vegetation of passive recovered salt marshes have a higher similarity in floristic composition (species pool) and salt marsh structure (low, medium, and high salt marsh), when compared with salt marshes in its natural state. We support this hypothesis in the work by Costa and Lousã (1989), Pullam (1988) and Almeida et al. (2014, 2016), which demonstrated that former reclaimed marshes which have been object of de-embankment or non-artificial tidal reactivation, present a vegetation composition with great resemblance with natural salt marshes.

The scope of this research is to discuss active recovery options and their effects on the ecological restoration of the salt marshes' habitats, under targeted interventions supported by the need to enhance ecosystem services, to compensate for habitat loss or to respond to a specific hazard, i.e coastal flooding. We aim to explore the vegetation composition of natural stabilized salt marshes and compare them with the vegetation development of nearby passive recovered areas in the southern Algarve region, in Portugal. These refer to unmanaged salt marshes of the Mediterranean biogeographic region: $\mathrm{N} 37^{\circ} 07.097^{\prime}$ W008 $30.189^{\prime}$ (Arade estuary) and $\mathrm{N}$ $37^{\circ} 07.991^{\prime}$ W008 $37.440^{\prime}$ (Alvor estuary).

Our objective is to discuss the vegetation similarities coming from recovery processes, rather active (induced and planned) or passive, rather than perform an analysis such as specie-by-specie comparison. It is intended to study the process of recovery as a whole, focusing on the method used and vegetation comparisons focusing within salt marshes sharing the same ecology and biogeographic region.

This combined analysis and the comparative approach may be useful to guide future interventions in salt marshes elsewhere because it analyses vegetation from managed and unmanaged marshes. It also provides a valuable comparison with the ecosystem in its natural state (natural salt marshes) The novelty of this work comes from the fact that Portuguese salt marshes are in the Mediterranean biogeographic region but facing the Atlantic Ocean. This specificity makes them very different as far as floristic composition is concerned, when compared with Atlantic salt marshes. Therefore, this research is able to provide valuable comparison of vegetation succession both in Atlantic and Mediterranean (Costa et al., 2009) salt marshes in different contexts of recovery (active or passive), trying to provide further insights into unmanaged salt marsh development.

\section{Methodology}

The methodology used in this paper relies on the literature review on coastal ecosystem recovery, bringing to light the scattered concepts on intervention options. We analyse and compare the results of vegetation recovery and the flora developments (frequency, cover) derived from active interventions (international examples) and passive recovery cases (Western Algarve's salt marshes).

Vegetation data have two origins: for international examples on salt marsh active recovery, we used floristic surveys found on the literature, which studied, analysed and compared vegetation of reference salt marshes and those emerging as a result of an active intervention (Table 1).

\subsection{Reference data set}

Literature review was made to assess examples of vegetation composition of reference salt marshes and species recovery studies carried out after a targeted intervention. Sources, goals and methods and general data about reference salt marshes and active recovered areas is synthesized in Table 2 . To note that the authors carefully selected examples of floristic surveys that followed BraunBlanquet (1979) scores method, in order to follow the same methodology used in the survey of unmanaged marshes (Portuguese case), despite the relevance of the work of others (i.e. Garbutt et al., 2006; Hughes et al., 2009). For the record, we excluded from the original surveys of Van Loon-Steensma et al. (2015) frequencies of algae, fungi, bryophytes (absent from the reference salt marsh but highly increasing in the MR survey) and arboreal species.

\subsection{Vegetation surveys}

Floristic surveys were conducted in Southwest Algarve during 2 complete years (2012-2014) in different salt marsh environments and periods to include floristic seasonality. Preparation for the floristic surveys was carried out according to the Zurich-Montpelier methodology in order to address floristic differences between marshes. The floristic surveys were conducted following the abundance/dominance scores method (Braun-Blanquet, 1979) by using sampling quadrates of $2 \mathrm{~m}^{2}$ along selected transects. The floristic surveys were conducted in randomly selected salt marsh areas covering as equally as possible the two types of unmanaged marshes ( $\mathrm{T}$ and $\mathrm{E}$ ), and also salt marshes in its natural state (natural salt marshes). For vegetation surveys and species list see S1 in Appendix A1. The degree of presence (Braun-Blanquet, 1979) was calculated to evaluate the differences in species richness between salt marsh areas. The presence is estimated in percentages of a species and classified according to a chosen scale into a set of 'classes of presence'. The classes were defined according to Costa et al., 2009: r (<6\%); + (6-10\%); I (11-20\%); II (21-40\%); III (41-60\%); IV (61-80\%); V (>81\%). Braun-Blanquet's 'cover-abundance' scale was used in the floristic surveys, but for the statistical analysis it was transformed using the average coverage of Lepš and Šmilauer (2003) and Portela-Pereira (2013): (5) 87.5\%; (4) 62.5\%; (3) $37.5 \%$; (2) $15 \%$; (1) $3 \%$; (+; r) $0.5 \%$. Nomenclature and ecological classification follows the main flora works by Castroviejo et al.,(1986-2007), Franco $(1971,1984)$, Franco and Rocha Afonso 
Table 1

Salt marsh reference data set by biogeographic region and intervention type.

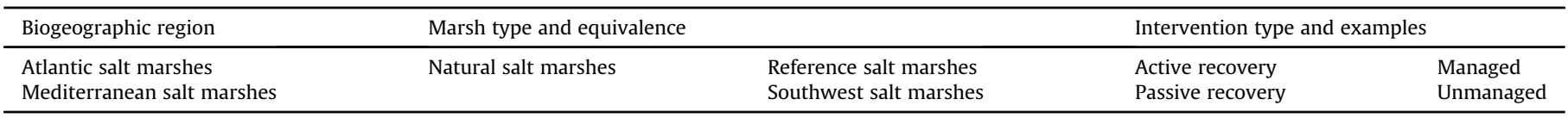

Table 2

Correspondence between reference and test salt marshes, goal, methods, and data involved.

\begin{tabular}{|c|c|c|}
\hline Goals/methods & Data & Author/site \\
\hline Aims: species pool, site suitability, and regional/local species availability & 70 sites & Wolters et al., 2005, 2008 \\
\hline Methods: species monitoring; surface elevation; saturation index; stepwise discriminant analysis & & Western Europe MR salt marshes \\
\hline Aims: investigating the composition of communities and their change over time on the MR site; & 145 & Mossman et al., 2012 \\
\hline Methods: Bray-Curtis similarity index; & relevés & Brancaster, North Norfolk - U.K. \\
\hline K-means cluster analysis & & \\
\hline Aims: vegetation trajectories of barrier island restored salt marshes (behind low dams) & 170 & Van Loon-Steensman et al., 2015 \\
\hline Methods: Species-by-species analysis; ordination by using a correspondence analyses (CA) & relevés & DutchWadden Sea - The Netherlands \\
\hline
\end{tabular}

(1994, 1998, 2003), and Rivas-Martínez (2005). This differentiation was adopted to understand the species adaptation and preference in unmanaged salt marshes.

\subsection{Data analysis}

A hierarchical classification, description, and floristic interpretation of test salt marshes was made using SYN-TAX 2000 (Podani, 2001). The vegetation data were hierarchically classified (UPGMA) using the Bray-Curtis coefficient, which results in a dissimilarity clustering of vegetation. Additional data on vegetation was calculated for supporting information (i.e frequency of occurrence; average coverage; degree of presence).

Moreover, a principal component analysis (PCA) was performed on unmanaged salt marshes, in which ordination was defined by the species cover-abundances. Here we used CANOCO software and selected the inter-species correlation option. Further on, we applied a multivariate analysis to arrange floristic surveys along the axes, based on their floristic composition (Capelo, 2003), this allowed us to test the importance of the local species pool.

We employed a species-by-species analysis (Van LoonSteensma et al., 2015) based on frequencies in both the test and the reference data sets. This method provided detailed insights into the characteristic species and those transitioning from pre-state to managed realignment salt marshes. The unavailability of reference floristic surveys made it impossible to develop a more robust statistical analysis.

For a comparison between and within groups (see Table 1), we applied the unweighted similarity index developed by Byers and Chmura (2007): $\mathrm{Si}=(2 \mathrm{~A} /[2 \mathrm{~A}+\mathrm{B}+\mathrm{C}]) * 100 \%$, where A equals the number of species the compared salt marshes have in common; $B$ stands for the species which are exclusive to salt marsh 1 ; and $C$ represents the species exclusive to salt marsh 2 - the closer to $100 \%$, the highest the index of similarity. This approach was used to overcome the availability of raw data on vegetation surveys which unable to perform more complex statistics. Using the similarity index $(\mathrm{Si})$ we were able to evaluate the closeness of the recovered vegetation towards the natural conditions (reference salt marshes), whenever it was active or passive process.

\section{Results}

\subsection{Unmanaged salt marshes}

Floristic surveys undertaken in unmanaged salt marshes revealed 61 different taxa. The vegetation is dominated by exclusive
(29\%) and preferential (20\%) species (Figs. 1 and 2). Ruderal species represent almost a third of the total species composition (29\%) and species preferring dune habitats represent $7 \%$. Invasive species represent $5 \%$ of the total taxa and the remaining $10 \%$ is distributed among fresh water species and halo-nitrophilous (see S1 in Appendix A1)

Average cover (Lepš and Šmilauer, 2003) according to scale grouping revealed the majority of species (47.5\%) cover on average less than $3 \%$ of the surveyed area. There is no evidence of average coverage equal or higher than $87.5 \%$. To better understand the distribution of the characteristic species, Fig. 3 represents the species coverage of the $15-67.5 \%$ scales. Halimione portulacoides (=Atriplex portulacoides) is among the most common species, the average coverage is $62 \%$, followed by the Sarcornornia species, which together form the most regular associations in lower/

\section{Species partition according to ecological classification}

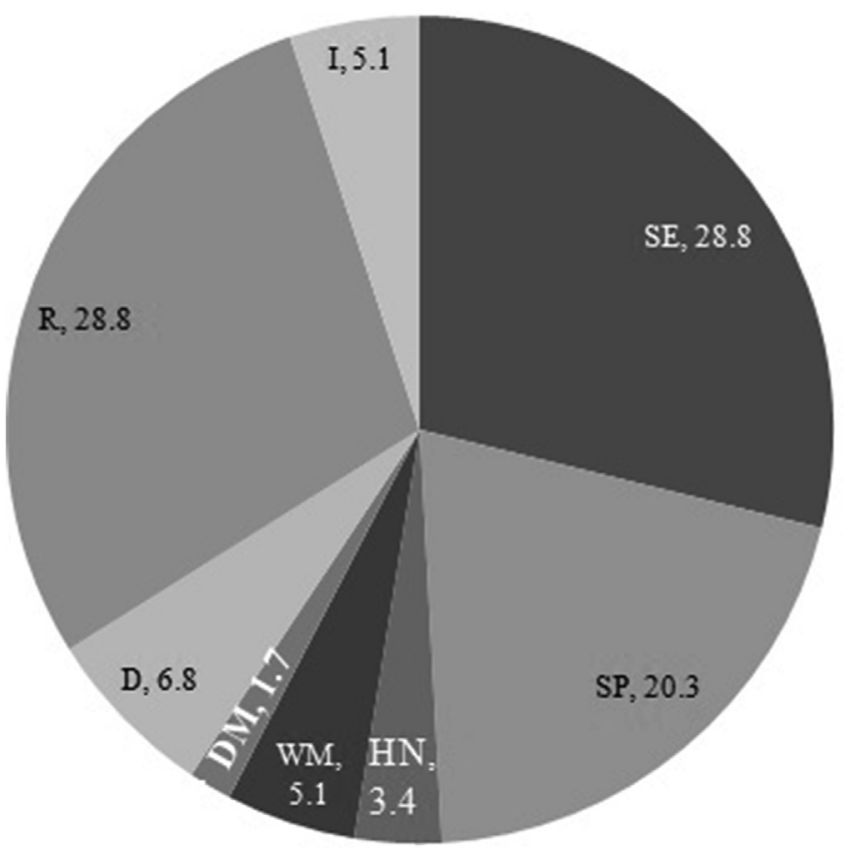

Fig. 1. Species partition according to ecological classification [SE salt marsh exclusive; SP salt marsh preferential; R ruderal; D dunes; HN halo-nitrophilous; I invasive; P parasite; WM wet meadows; DM dry meadows]. 


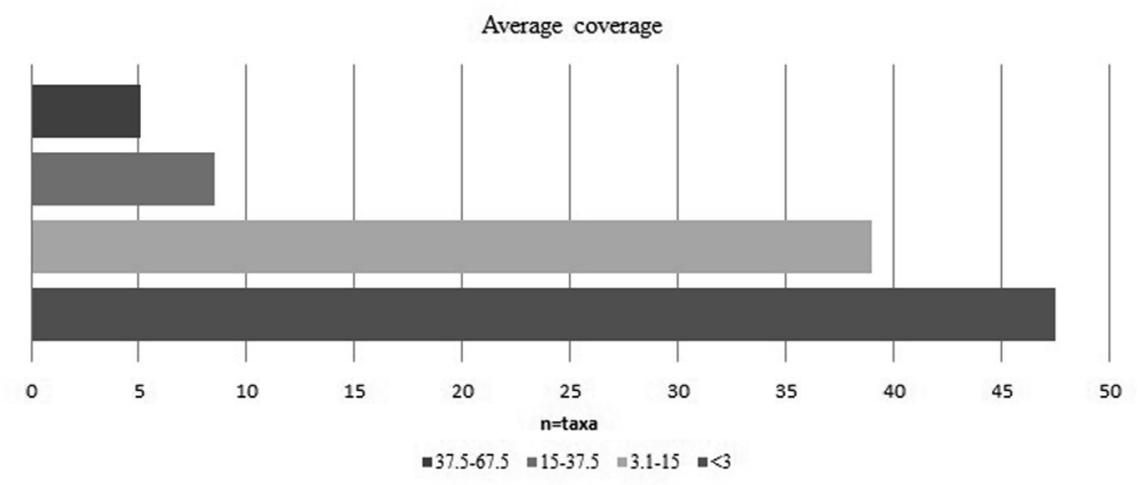

Fig. 2. Average coverage according to scales (\%).

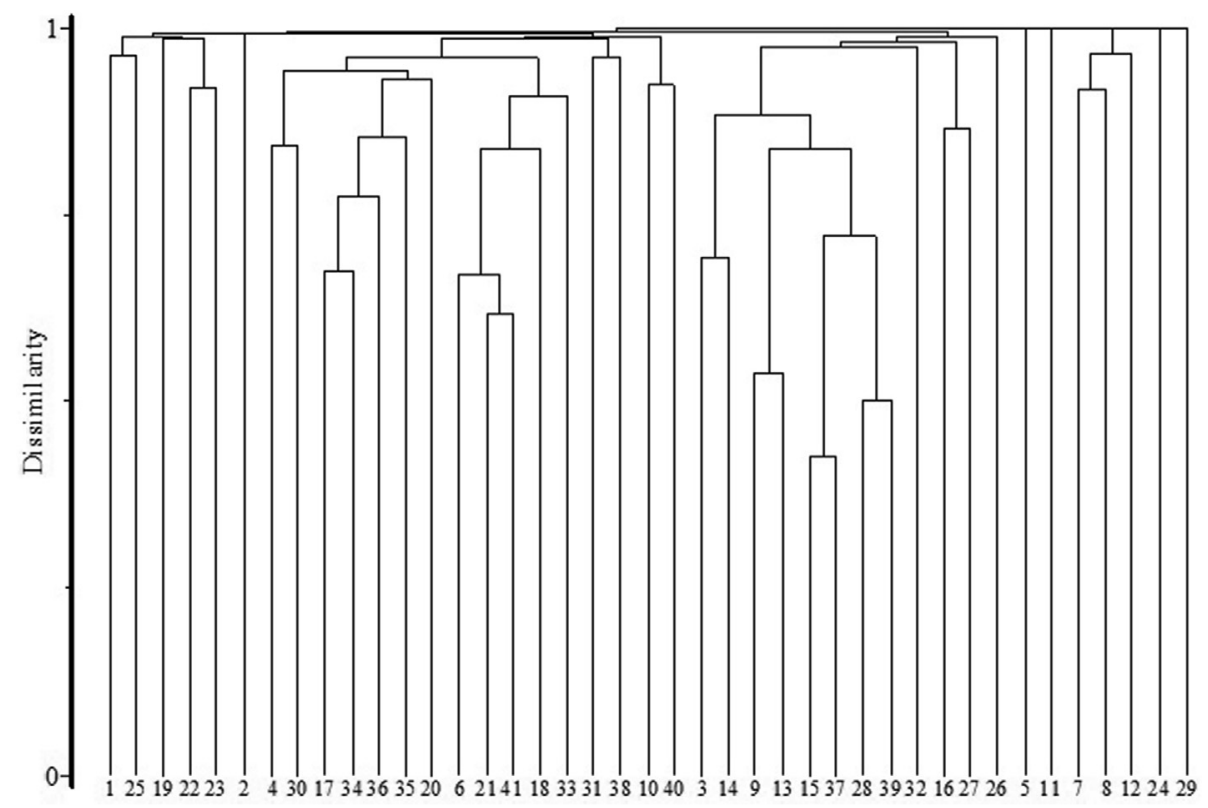

Fig. 3. UPGMA performed for Natural salt marshes.

medium salt marshes in Portugal (Costa et al., 2012) (see Figs. 4 and $5)$.

\subsection{Natural salt marshes ( $N$ )}

The UPGMA analysis showed that characteristic species of salt marshes appear in well-defined groups, representing a clear hierarchical partition in ecological terms (Fig. 3). Characteristic species of high marsh stand out from the other exclusive or preferential species.

Salt marsh, exclusive and preferential species are grouped separately but sequentially and within this larger group, it is possible to find Limonium and Artemisia genus. Low marsh Spartina maritima and Salicornia ramosissima mark the close-up of the first group.

In the second group of species it can be highlighted the presence of the invasive Oxalis pes-carpae, linked with ruderal Calendula avensis and Carpobrotus edulis. Other marsh invasive, Cotula coronopifolia appears linked with Hypochaeris radicata, traditional of wet meadows and Polypogon maritimus, which is a salt marsh preferential.
Most of the ruderal species are within the same large group (i.e. Mellilotus segetalis, Scorpius vermiculata, Emex spinosa or Medicago polymorpha). The last group is composed of a miscellaneous of dune species: halo nitrophilous (Frankenia laevis), dry meadows (Asparagus albus), and fresh water (Bolboschoenus maritimus).

Natural salt marshes: 1) Artemisia campestris var marítima; 2) Artemisia crithmifolia; 3) Artemisia gallica; 4) Arthrocnemum macrostachyum; 5) Aster tripolium ssp. Pannonicus; 6) Atriplex halimus; 7) Atriplex prostrata; 8) Bolboschoenus maritimus var. compactus; 9) Bromus lanceolatus; 10) Carpobrotus edulis; 11) Cistanche phylipaea; 12) Cotula coronopifolia; 13) Digitaria sanguinalis; 14) Elytrigia elongata; 15) Elytrigia juncea; 16) Frankenia leavis; 17) Halimione portulacoides); 18) Inula crithmoides; 19) Juncus acutus; 20) Juncus maritimus; 21) Limoniastrum monopetalum; 222) Limonium algarvense; 23) Limonium lanceolatum; 24) Limonium narbonense; 25) Limonium vulgare; 26) Medicago polymorpha; 27) Oxalis pes-caprae; 28) Polypogon maritimus; 29) Puccinellia iberica; 30) Puccinellia marítima; 31) Salicornia ramosíssima; 32) Salsola soda; 33) Salsola vermiculata; 34) Sarcocornia perennis ssp. alpini; 35) Sarcocornia perennis ssp. perennis; 36) Sarcocornia pruinosa; 37) Sonchus maritimus; 38) Spartina marítima; 39) Spergularia bocconei; 40) Suaeda 


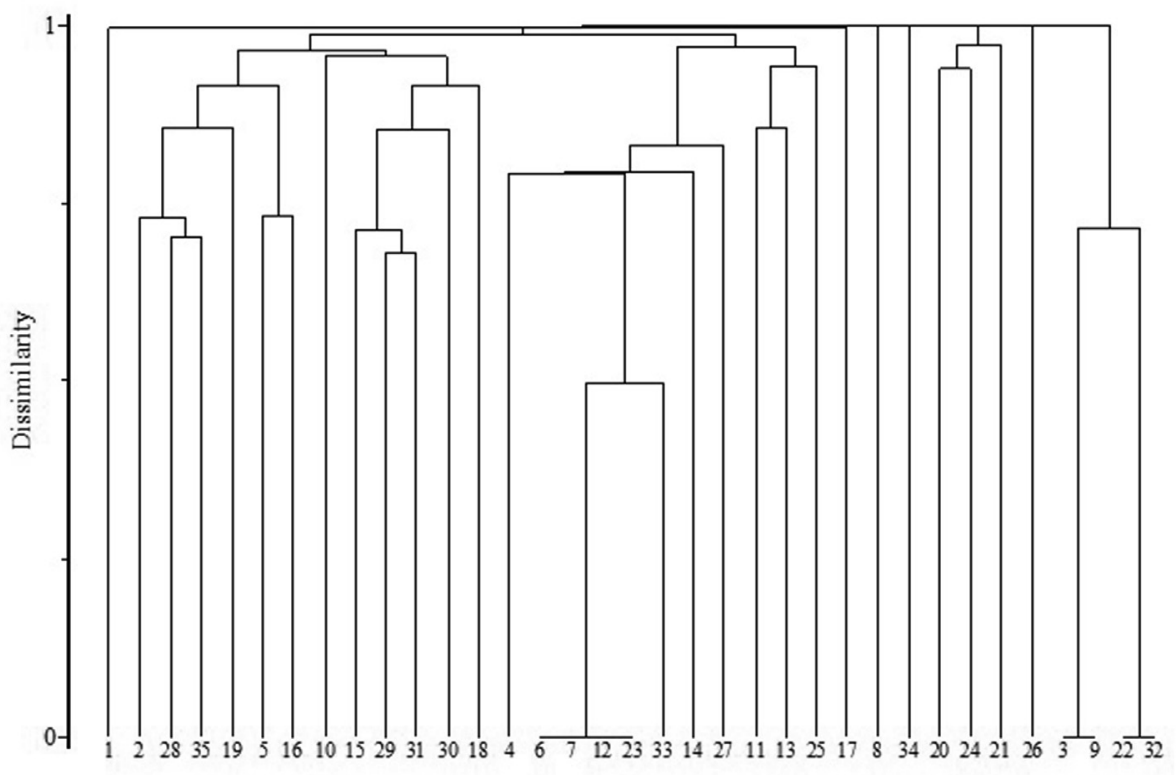

Fig. 4. UPGMA performed for Tidally restored salt marshes (T).

albescens; 41) Suaeda vera.

\subsection{Passive recovered marshes}

Tidally restored salt marshes $(\mathrm{T})$ : in contrast with natural salt marshes, there is a less evidence of species partition and organization. In the case of Alvor, ruderal species (i.e. Anagallis arvensis, Medicago polymorpha, Spergularia bocconei) appear associated sequentially with high marsh and fresh water species. At the tail of the group, we find the exclusive species. Arade's UPGMA draws similarities with natural salt marshes, as characteristic species of high, medium and low marshes are grouped sequentially; followed by a large grouping of ruderal and salt marsh preferential species. The localisms Limonium algarvence and Limonium lanceolatum are grouped together with the invasive Oxalis pes-carpae, Spartina maritima, Juncus acutus, and Puccinelia maritima are linked directly at the top.

Tidally restored salt marshes (T): 1) Artemisia gallica; 2) Arthrocnemum macrostachyum; 3) Aspargos albus; 4) Aster tripolium ssp. Pannonicus; 5) Atriplex halimus; 6) Atriplex patula; 7) Atriplex prostrata; 8) Bolboschoenus maritimus var. compactus; 9) Sedum sediforma; 10) Cistanche phylipaea; 11) Elytrigia elongata; 12) Emex spinosa; 13) Ferula tingitana; 14) Frankenia leavis; 15) Halimione portulacoides); 16) Inula crithmoides; 17) Juncus acutus; 18) Juncus maritimus; 19) Limoniastrum monopetalum; 20) Limonium algarvense; 21) Limonium lanceolatum; 22) Medicago polymorpha; 23) Melilotus segetalis; 24) Oxalis pes-caprae; 25) Puccinellia iberica; 26) Puccinellia marítima; 27) Salicornia ramosíssima; 28) Salsola vermiculata; 29) Sarcocornia perennis ssp. alpini; 30) Sarcocornia pruinosa; 31) Sarcocornia perennis ssp. perennis; 32) Scorpiurus vermiculata; 33) Sonchus maritimus; 34) Spartina marítima; 35) Suaeda vera.

Enclosed mixed marshes (E): in Alvor's enclosed mixed marshes, there are three large groups: the first group mixes the main low and medium salt marsh characteristic species (i.e. Arthrocnemum macrostachyum, Halimione portulacoides, Salicornia ramosissima, Sarcocornia. perennis subsp. alpini and Sarcocornia pruinosa); the second group is composed of fresh water and ruderal species, as well as the invasive Cotula coronopifolia; the last group aggregates few ruderal and the salt marsh preferential (i.e. Salsola vermiculata, Suaeda albescens or Sonchus maritimus). Considering Arade's EMM, the sampled area reveals a similar composition to natural salt marshes. High and low salt marsh characteristic species are very well defined and grouped separately, corresponding to the first and third groups, respectively. The middle group is composed of a mix of preferential species (Elytrigia juncea, Elytrigia elongata), with ruderal species. We would like to highlight the absence of invasive species.

Enclosed mix marshes (E): 1) Arthrocnemum macrostachyum;2) Atriplex halimus; 3) Bolboschoenus glaucus; 4) Brachyponium phoenicoides; 5) Bromus lanceolatus; 6) Carpobrotus edulis; 7) Cotula coronopifolia; 8) Halimione portulacoides; 10) Hypochaeris radicata; 11) Juncus acutus; 12) Juncus maritimus; 13) Medicago polymorpha; 14) Melica minuta; 15) Melilotus segetalis; 16) Polycnemum arvence; 17) Polypogon maritimus; 18) Puccinellia iberica; 19) Puccinellia marítima; 20) Salicornia ramosíssima; 21) Salsola vermiculata; 22) Sarcocornia perennis ssp. Perennis; 23) Sarcocornia perennis ssp. Alpini; 24) Sarcocornia pruinosa; 25) Sonchus maritimus; 26) Suaeda albescens; 27) Suaeda vera; 28) Taraxacum officinale.

Fig. 6 shows different typologies share exclusive and preferential species. Enclosed mixed marshes (E) seem to gather higher floristic diversity, as ruderal, invasive species and species that are typical of other habitats fall within this typology. Ubiquitous species (ruderal, fresh-water, dry meadows) appear to be almost transversal to the three typologies, but with low penetration in natural salt marshes. The chart shows ubiquitous species in the central axes, corresponding to their wider distribution and preference for habitats with signs of disturbance (enclosed mixed marshes and some tidally restored salt marshes); allowing the entrance of some invasive species and adjacent habitat species (i.e. dunes). Salt marsh preferential species (mostly within tidally restored salt marshes) tend to be of broader onset, showing a distribution that is closer to natural salt marshes.

\subsection{Similarity indexes}

Managed salt marshes frequently report to old deembankments where marshes were reclaimed for agricultural usages Wolters et al. $(2005,2008)$ and therefore there is a need to give 


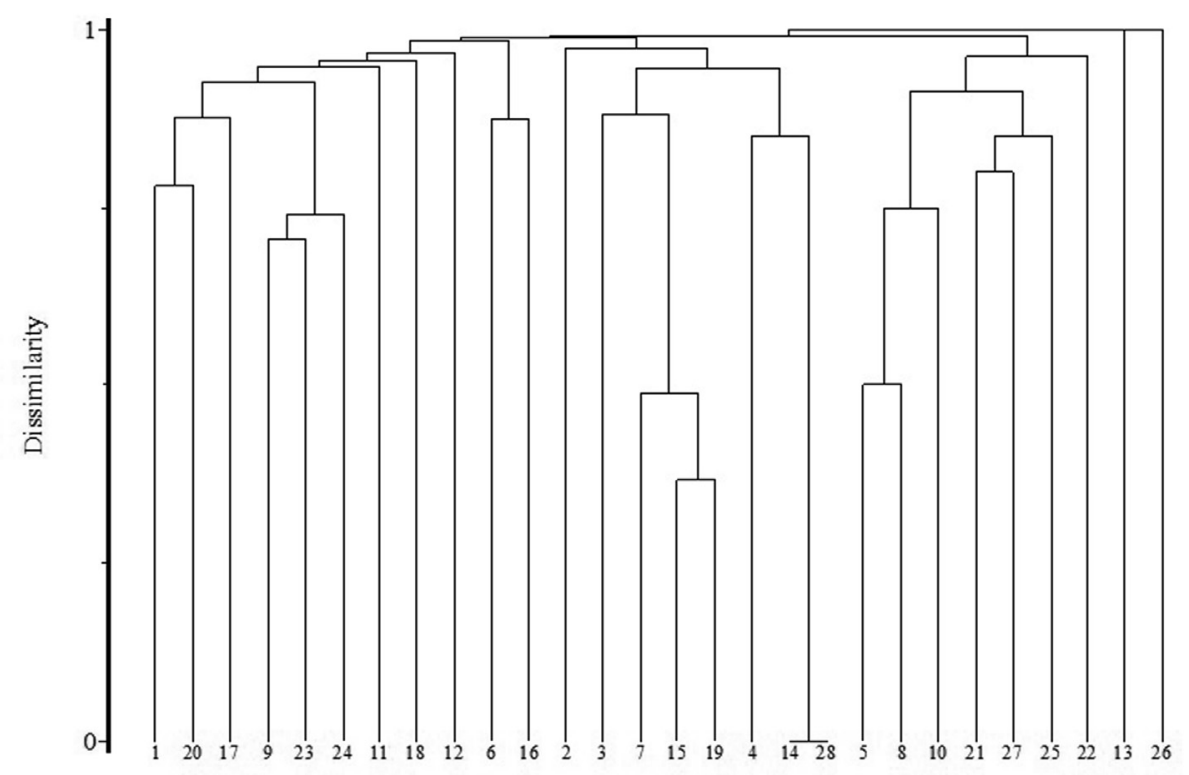

Fig. 5. UPGMA performed for Enclosed mix marshes (E).

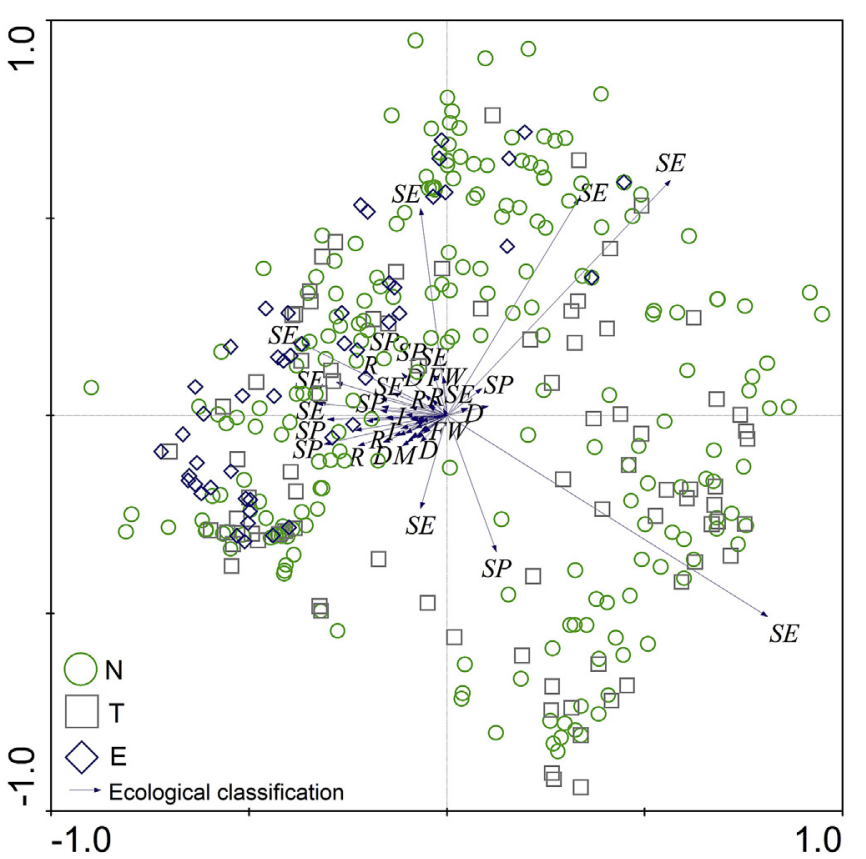

Fig. 6. Main groups of salt marsh communities according to ecological classification Legend: natural $(\mathrm{N})$, tidally restored salt marshes $(\mathrm{T})$ and enclosed mixed marshes (E), SE-salt marsh exclusive; SP-salt marsh preferential; R-ruderal; I-invasive; FW-fresh water; DM-dry meadows; D-dunes.

back the ecosystem's natural state. This process is held by decision makers and is policy oriented towards specific objectives, as tidal reactivation (Byers and Chmura, 2007; Davy et al., 2011) or the opposite as building a stone barrier to prevent erosion, and strangle the tidal flow (Van Loon-Steensma et al., 2015). The Similarity indexes performed to evaluate the degree of resemblance between species of different recovery processes showed that in the cases of managed salt marshes, the indexes are endemically lower that those performed to unmanaged salt marshes (see Table 3 ).

The case $\mathrm{T}$ (tidally restored salt marshes) delivered $88.7 \%$ of similarity. Among the 43 common species, they share the salt marsh characteristic species and also most of the ruderal species. Only three are exclusive to the tidally restored habitat: the ruderal A. arvensis and Sedum sediforme, and the dune species Mesembryanthemum nodiflorum. The Limonium genus is mostly exclusive to natural salt marshes. Considering the case $\mathrm{E}$ (enclosed mix marshes) it share 30 species with natural salt marshes. This includes salt marsh exclusive and preferential species, with the exception of S. maritima, Myriolimion diffusum, L. lanceolatum, and Limonium narbonense. The six species that appear only in the E case surveys are predominantly ruderal (i.e. Cynara cardunculus, Melica minuta) - here the similarity is of $68.2 \%$.

\subsection{Discussion: recovery or restoration?}

Recovery is frequently used to describe all forms of improving ecosystem services, functions, and goods, embracing other additional concepts, such as restoration, re-creation, enhancement, and adaptation (Elliott et al., 2007). Central to the entire concept of recovery is the action: passive or active. Elliot et al. (2007) present a definition of recoverability, which is the concept to be used in this paper: recoverability is the ability of a habitat, community or individual (or individual colony) of species to redress damage sustained as a result of an external factor'. Formally, ecosystems that need any intervention are triggered by natural or human change; furthermore, human involvement is required to react to stressors, re-establish lost habitats, and act as compensatory measures (active recovery); or the existence of certain natural processes within ecosystem functions will contribute to healing through passive recovery (Elliott et al., 2007; Duarte et al., 2013). Concepts underlying passive recovery are connected with the internal aspects of the ecosystem, such as its resilience and carrying capacity, plus the external factors that create the opportunity, such as abandonment or causality (adaptation versus compensation). The work by Hughes et al., 2009 revealed that external factors such as constant sea level rise may induce rapid erosion of the marsh creeks, leading to extreme channelling and marsh vegetation dieback, putting into evidence the need of a targeted intervention to avoid marsh submergence and loss (i.e active recovery).

Studies on active recovery tend to analyse the degree of success 
Table 3

Similarity index results and areas of application.

\begin{tabular}{|c|c|c|}
\hline Reference site & Recovery technique & $\mathrm{Si}$ \\
\hline North Atlantic U.S.A. & Active recovery: tidal reactivation & $\begin{array}{l}\text { Case } 1=69.7 \\
\text { Case } 2=42.1\end{array}$ \\
\hline North Atlantic Europe & Active recovery: restrict tidal flow and prevent erosion & 57.3 \\
\hline Natural salt marshes & Unmanaged passive recovered & Case $\mathrm{T}=88.7$ \\
\hline Mediterranean region (Southwest Algarve, Portugal) & & Case $\mathrm{E}=68.2$ \\
\hline
\end{tabular}

undertaken by the project. As Mossman et al. (2012) showed by monitoring a managed realignment site in a year basis (during 5 years), species colonization and arrival order determine the success of the intervention: ruderal species (i.e. Atriplex prostrata, Festuca rubra) were absent in the first year but tended to colonize significantly in the second and third years - ruderal i.e. Cochlaria anglica appears only in the last year of monitoring; and salt marsh preferential (i.e. Spergularia media, Juncus maritimus, Triglochin maritimam) colonize from the second year on and become less frequent by the end of the fourth year. Third and fourth years represent the state of maturity for the majority of species (higher frequencies and mean covers registered). Comparing to passive recovery areas in Southwest Portugal, the former agricultural use was abandoned 30-40 years ago, leading to a progressive colonization of species from the regional and local species pool (Almeida et al., 2014). This time-gap between the results from active or passive recovery may lead to narrow the focus on considering a target intervention with fastest results, or a non deliberated intervention which can take decades to recover but with highest similarity indexes.

Conducting an active recovery project guides the path of the intervention, but also has an influence over its results, whether in terms of the species pool or the possibility of colonization (Doody, 2008; Hughes et al., 2009). Despite almost 60\% of similarity index, post-intervened salt marsh documented by Van Loon-Steensma et al. (2015) revealed a reduction in halophytes diversity, which relates to a great penetration of freshwater communities into the managed site, but also with a reduction of ruderal species.

Considering the two types of unmanaged marshes, (T) present a high similarity index that (E), when compared with natural salt marshes. This resemblance is related with the previous situation of the reclamation process. In (E) marshes with a past occupation by agriculture activities, the salt marsh vegetation was ripped out when dyking took place for providing suitable arable lands (Pullam, 1988). In the cases of (T), the process of dyking was meant for salt production, and therefore no other ecosystem was truly implemented instead (Almeida et al., 2014). The establishment of target species in $(\mathrm{T})$ was possible without human intervention due to the presence of those species in the community species pool (Wolters et al., 2008), i.e. Spartina maritima tussocks colonizing the low marsh in (T) areas (Doody, 2008). Spartina maritima is prolific from rhizome fragments, showing higher sediment elevation in the center of the patch but also lower density of shoots (Marchant and Goodman, 1969; Sánchez et al., 2001), which makes it a weak candidate for replantation projects for active recovery in salt marshes, contrary to what happens with Spartina densiflora or Spartina anglica which propagules by seeds (Doody, 2008; MateosNaranjo et al., 2008).

On the other hand, (E) lower similarity than (T) is derived from successive embankments and agricultural exploitation, since halophytes were replaced by beet or barley cultures (Alvim, 1964). The multivariate analysis allowed us to understand the species distribution according to ecological classification and salt marsh typology, nevertheless salt marsh exclusive species (SE) are represented in the outer quadrants, revealing a narrow distribution, particularly targeting natural and tidally restored salt marshes.
However, we can see from the similarities with natural salt marshes that many species established and may develop successfully. In these cases, there is a more significant assortment of ubiquitous species than the characteristic species registered in the 5-year period studied by Mossman et al. (2012). Wolters et al. $(2005,2008)$ demonstrated an average of $74 \%$ of the species present in the local species pool was established in the restoration sites at most 13 years after de-embankment.

Although for the regional species pool, only an average of $45 \%$ of the species managed to establish for passive recovery success. The great relevance of the availability and dispersal of the target species from the natural salt marsh to the restored area, in which target species should arrive spontaneously (Wolters et al., 2008), is demonstrated. Without recovery or any other managed realignment objectives guiding the destiny of the unmanaged salt marshes, the species going from natural salt marshes to the other topologies are faithful to the natural salt marsh species pool and structure (Arthrocnemum macrostachyum, Halimione portulacoides, Sarcocornia perennis, Sarcocornia perennis subsp. alpini and Sarcocornia pruinosa). Gaps are found in low marsh pioneer S. maritima or Bolboschoenus maritimus, related with elevation and incoming tide succession. Despite this fact, biodiversity is an unnecessary gain of this particular ecological evolution, which in active recovery projects can be easily controlled, as well as invasive species penetration.

This study may contribute to further investigation on the causes of colonizing species derived from passive recovery and provide a framework for guided interventions to enhance salt marsh passive recovery, to be applied to unmanaged salt marshes elsewhere.

\section{Final remarks}

Species recovery capability is of various origins and within this investigation we are circumscribing it to the frequency of occurrence after human interventions. Additionally, plant communities on restored salt marshes tend to show a slower development when compared with natural sites. Despite the causes of the differences in the colonization patterns of restored salt marshes, and regarding this research, species appear to be within a local and regional species pool. Unmanaged salt marshes' characteristic species assemble with those found in natural salt marshes, but are less frequent and present some ruderal species $(\mathrm{T})$ or even show the penetration of some other species from adjacent habitats (E).

Our findings are consistent with our hypothesis: a higher similarity in the flora of unmanaged salt marshes can be found comparing with both natural salt marshes and managed salt marshes. Additionally, results attest that passive recovery delivers a higher similarity index supported by the regional and local species pool. Nevertheless, active recovery can play a fundamental role when environmental catastrophes take place or characteristic species are unable to germinate or root.

Accidental breaching dikes or structures decay may produce similar results of managed realigment, as well as floristic similarities even after long-time periods, which may raise doubts over sustainability of these options. A destruction of a natural habitat 
can be replaced with an artificial one, comprising biodiversity changes and other environmental impacts, regardless the ecological outcome (Champman \& Underwood, 2011).

Here lies the ultimate challenge: Do we want to create new salt marshes to achieve more or improved ecosystem services? Or should we enhance marsh characteristics through recovery to accomplish environmental metrics and account for coastal defence?

\section{Acknowledgements}

The authors would like to thank the financial support of the Portuguese Foundation for Science and Technology, in which the work developed by D.Almeida was funded (grant reference SFRH/ $\mathrm{BD} / 77252 / 2011)$.

\section{Appendix A. Supplementary data}

Supplementary data related to this article can be found at http:// dx.doi.org/10.1016/j.ecss.2017.04.018.

\section{References}

Almeida, D., Neto, C., Esteves, L.S., Costa, J.C., 2014. The impacts of land-use changes on the recovery of salt marshes in Portugal. Ocean Coast. Manag. 92, 40-49.

Almeida, D., Rocha, J., Neto, C., Arsénio, O., 2016. Landscape metrics applied to formerly reclaimed saltmarshes: a tool to evaluate ecosystem services? Estuar. Coast. Shelf Sci. 181, 100-113. http://dx.doi.org/10.1016/j.ecss.2016.08.020.

Alvim, A.J.S., 1964. Possibilidades do aproveitamento dos sapais em Portugal. Conferência proferida na sala de sessões da junta distrital de faro, 9 abril, Separata A Agricultura e o I Plano de Fomento.

Boorman, L., Hazelden, J., Boorman, M., 2002. New salt marshes for old - salt marsh creation and management. Littoral 2002. In: EUROCOAST. The Changing Coast. EUROCOAST/EUCC Porto, Portugal.

Braun-Blanquet, J., 1979. In: Blume, H. (Ed.), Fitosociologia. Bases para el estudio de las comunidades vegetales. Madrid.

Byers, S., Chmura, G., 2007. Salt marsh vegetation recovery on the bay of fundy. Estuaries Coasts 30, 869-877.

Capelo, J., 2003. Conceitos e métodos da Fitossociologia. Formulação contemporânea e métodos numéricos de análise da vegetação, ISBN 972-95736-89, p. 107. Estação Florestal Nacional, Sociedade Portuguesa de Ciências Florestais.

Castillo, J.M., Mateos-Naranjo, E., Niev, F.J., Figueroa, E., 2008. Plant zonation at salt marshes of the endangered cordgrass Spartina maritima invaded by Spartina densiflora. Hydrobiologia 614, 363-371.

Castroviejo, S., Laínz, M., López González, G., Monserrat, P., Muñoz Garmendia, F., Paiva, J., Villar, L. (Eds.), 1986-2007. Flora Iberica. Volumes I-VIII, X, XIV, XV, XVIII, XXI. Real Jardín Botánico de Madrid, CSIC, Madrid.

Chapman, M.G., Underwood, A.J., 2011. Evaluation of ecological engineering of "armoured" shorelines to improve their value as habitat. J. Exp. Mar. Biol. Ecol. 40, 302-313.

Costa, J.C., Lousã, M., 1989. Communautes Psammophiles et Halophiles du "Ria de Alvor". Colloques phytosociologiques. XVIII, Phytosociologie littorale et Taxonomie. Bailleul 1989, 119-135.

Costa, J.C., Neto, N., Arsénio, P., Capelo, J., 2009. Geographic variation among Iberian communities of the exotic halophyte Cotula coronopifolia. Bot. Helvetica 119, 53-61.

Costa, J.C., Neto, C., Aguiar, C., Capelo, J., Espírito-Santo, M.D., Honrado, J., PintoGomes, C., Monteiro-Henriques, T., Sequeira, M., Lousã, M., 2012. Vascular plant communities in Portugal (continental, the azores and Madeira). Glob. Geobotany Int. J. Geobotanic Sci. 2.

Crépin, A.S., 2005. Incentives for wetland creation. J. Environ. Econ. Manag. 50, $598-616$.

Davy, A.J., Brown, M.J.H., Mossman, H.L., Grant, A., 2011. Colonization of a newly developing salt marsh: disentangling independent effects of elevation and redox potential on halophytes. J. Ecol. 99, 1350-1357.

Doody, J.P., 2008. Coastal systems and continental margins: salt marsh Conservation. Manag. Restor. 12. Springer.

Doody, J.P., 2013. Coastal squeeze and managed realignment in southeast England, does it tell us anything about the future? Ocean Coast. Manag. 79, 34-41.

Duarte, C.M., Losada, I.J., Hendriks, I.E., Mazarrasa, I., Marbà, N., 2013. The role of coastal plant communities for climate change mitigation and adaptation. Nat. Clim. Change 3, 961-968.
Elliott, M., Burdon, D., Hemingway, K.L., Apitz, S.E., 2007. Estuarine, coastal and marine ecosystem restoration: confusing management and science - a revision of concepts. Estuar. Coast. Shelf Sci. 74, 349-366.

English, E.P., Peterson, C.H., Voss, C.M., 2009. Ecology and Economics of Compensatory Restoration.

Esteves, L.S., 2013. Is managed realignment a sustainable long-term coastal management approach? J. Coast. Res. 933-938.

Esteves, L.S., 2014. Managed Realignment a Viable Long-term Coastal Management Strategy? Springer Briefs in Environmental Science, New York.

Franco, J.A., 1971. Nova Flora de Portugal (Continente e Açores) Volume I, Lycopodeaceae-Umbelliferae (Lisboa, Portugal, Author's edition).

Franco, J.A., 1984. Nova Flora de Portugal (Continente e Açores) Volume II., Clethraceae-Compositae (Lisboa, Portugal, Author's edition).

Franco, J.A., Rocha Afonso, M.L., 1994. Nova Flora de Portugal (Continente e Açores) Volume III (Fasc. 1) (Lisboa, Portugal, Escolar Editora).

Franco, J.A., Rocha Afonso, M.L., 1998. Nova Flora de Portugal (Continente e Açores) Volume III (Fasc. 2) (Lisboa, Portugal, Escolar Editora).

Franco, J.A., Rocha Afonso, M.L., 2003. Nova Flora de Portugal (Continente e Açores) Volume III (Fasc. 3) (Lisboa, Portugal, Escolar Editora).

Friess, D., Möller, I., Spencer, T., 2008. Case Study: Managed Realignment and the Re- Establishment of Salt Marsh Habitat (Freiston Shore, Licolnshire, United Kingdom, Geomorphology).

Garbutt, A., Wolters, M., 2008. The natural regeneration of salt marsh on formerly reclaimed land. Appl. Veg. Sci. 11 (3), 335-344. http://dx.doi.org/10.3170/20087-18451.

Garbutt, R.A., Reading, C.J., Wolters, M., Gray, A.J., Rothery, P., 2006. Monitoring the development of intertidal habitats on former agricultural land after the managed realignment of coastal defences at Tollesbury, Essex. UK. Mar. Pollut. Bull. 53, 155-164.

Hughes, Z.J., FitzGerald, D.M., Wilson, C.A., Pennings, S.C., Wie ski, K Mahadevan, A., 2009. Rapid headward erosion of marsh creeks in response to relative sea level rise. Geophys. Res. Lett. 36, L03602. http://dx.doi.org/10.1029/ 2008 GL036000.

Lepš, J., Šmilaue, r P., 2003. Multivariate Analysis of Ecological Data Using CANOCO. Cambridge University Press, Cambridge.

Marchant, J., Goodman, P., 1969. Spartina maritima (curtis) fernald. J. Ecol. 57, 287-291.

Mateos-Naranjo, E., Redondo-Gómez, S., Luque, C.J., Castellanos, E.M., Davy, A.J., Figueroa, M.E., 2008. Environmental limitations on recruitment from seed in invasive Spartina densiflora on a southern European salt marsh. Estuar. Coast. Shelf Sci. 79, 727-732.

Mazik, K., Musk, W., Dawes, O., Solyanko, K., Brown, S., Mander, L., Elliott, M., 2010. Managed realignment as compensation for the loss of intertidal mudflat: a short term solution to a long term problem? Estuar. Coast. Shelf Sci. 90, 11-20.

Möller, I., 2006. Quantifying salt marsh vegetation and its effect on wave height dissipation: results from a U.K. East coast salt marsh. Estuar. Coast. Shelf Sci. 69, 337-351.

Morris, R., 2013. Managed realignment as a tool for compensatory habitat creation - a re-appraisal. Ocean Coast. Manag. 73, 82-91.

Mossman, H.L., Brown, M.J.H., Davy, A.J., Grant, A., 2012. Constraints on salt marsh development following managed coastal realignment: dispersal Limitation or environmental Tolerance? Restor. Ecol. 20, 65-75.

Podani, J., 2001. SYN-TAX 2000, Computer Program for Data Analysis in Ecology and Systematics (For Windows 95, 98\&NT) User's Manual. Scientia Publishing, Hungary.

Portela-Pereira, E., 2013. Análise Geobotânica dos Bosques e Galerias Ripícolas da Bacia Hidrográfica do Tejo em Portugal. PhD Thesis. University of Lisbon.

Pullam, R.A., 1988. A survey of the past and present wetlands of western Algarve, Portugal. Liverp. Pap. Geogr. 2, 99 pp.

Rivas-Martínez, S., 2005. Notions on dynamic-catenal phytosociology as a basis of landscape science. Plant Biosyst. 139, 135-144.

Sánchez, J.M., SanLeon, D.G., Izco, J., 2001. Primary colonisation of mudflat estuaries by Spartina maritima (Curtis) fernald in Northwest Spain: vegetation structure and sediment accretion. Aquatatic Bot. 69, 15-25.

Stagg, C.L., Mendelssohn, I., 2010. Restoring ecological function to a submerged salt marsh. Restor. Ecol. 18, 10-17.

Strange, E., Galbraith, H., Bickel, S., Mills, D., Beltman, D., Lipton, J., 2002. Determining ecological equivalence in service-to-service scaling of salt marsh restoration. Environ. Manag. 29, 290-300.

Van Loon-Steensma, J.M., Van Dobben, H.F., Slim, P.A., Huiskes, H.P.J., Dirkse, G.M., 2015. Does vegetation in restored salt marshes equal naturally developed vegetation? Appl. Veg. Sci. 18, 674-682.

Wolters, M., Garbutt, A., Bakke, J.P., 2005. Salt-marsh restoration: evaluating the success of de-embankments in north-west Europe. Biol. Conserv. 123, 249-268.

Wolters, M., Garbutt, A., Bekker, R.M., Bakker, J.P., Carey, P.D., 2008. Restoration o salt-marsh vegetation in relation to site suitability, species pool and dispersal traits. J. Appl. Ecol. 45, 904-912.

Zedler, J.B., West, J.M., 2008. Declining diversity in natural and restored salt marshes: a 30-year study of Tijuana estuary. Restor. Ecol. 16, 249-262. 